\title{
Stock Clustering Effect from Weekly Equity Options
}

\author{
Ge Zhang, Haiyang Chen, and Francis Cai
}

\begin{abstract}
Derivatives trading has become more interactive with equity transactions recently. One of those interactions is the stock clustering effect around option expiration days. This paper examines stock clustering effects from 2010 to 2012 when weekly equity options became available to the public. With 96 common stocks with weekly options traded in the available period, we show that stock clustering effect still exists on expiration days for listed monthly options, but this effect is much weaker for newly listed weekly options. Besides studying this average sample effect, we find an interesting result when we take a closer look at firm-specific effect. Only a limited number of firms have this clustering effect, and close to three quarters of the firms show no clustering effect at all. All these results demonstrate that stock clustering on option expiration days is not uniform for all stocks.
\end{abstract}

Index Terms-Stock clustering, weekly options, expiration dates.

\section{INTRODUCTION}

Derivative trading becomes increasingly important in financial markets today. More derivative contracts are introduced into the market and they attract large trading volumes. It is important for economists to understand the interaction between these derivative contracts and underlying financial assets.

One of the interactions is the stock clustering effect on option expiration days. That is, minutes before options expire, stock prices are close to or at one of the option strike prices. This tendency for stocks to close at one of the option strike prices on option expiration days (see Harris (1991)[1], Krishnan and Nelken (2001)[2], Ni, Pearson and Poteshman (2005)[3]), together without any important stock-specific news announcements from financial markets, has been referred as the stock clustering effect. This issue of stock clustering effect has attracted a lot of interests from both the academics and industry. A number of researchers study the clustering effect in various financial assets. For example, Ap Gwilym and Verousis (2013)[4] find clustering in equity options. Chung and Chiang (2006)[5], Golez and Jackwerth (2012)[6] Schwartz, Van Ness and Van Ness (2004)[7] study clustering in futures. Ohta (2006)[8] analyzes this effect in Japanese equity market.

When a stock displays this clustering effect, its movement deviates from random walk, and becomes predictable on option expiration days. During the last technology bubble period, traders observed frequent stock clustering effects in technology stocks. Recently traders also observed that some smart groups have advance information about closing price

Manuscript received April 25, 2013; revised June 30, 2013.

The authors are with William Patterson University, Wayne, NJ 07074 (e-mail: zhangg2@wpunj.edu, chenh@wpunj.edu, caif@wpunj.edu). on option expiration days and their high success rate in trading options could not be explained by normal trading behavior. It is thus important to have more research on the existence and the cause of the stock clustering effect.

In this paper, we use the recently introduced weekly equity options to further analyze this stock clustering issue. Since June 2010, CBOE has introduced weekly options for certain common stocks. With these weekly options, stock clustering goes from a once-a-month effect (on the expiration days of the monthly options) to a once-a-week effect. It is important to assess whether stock clustering effect occurs on the expiration days of these weekly options as well. This paper fills this void. In addition, with the introduction of decimal quotes, and the prevalence of high frequency trading, it is necessary to reevaluate whether stock clustering is still a wide spread phenomenon. Our paper contributes to evaluating those important effects with the newly listed weekly options.

This paper also takes a closer look at the individual stock level rather than the average sample effect. To our knowledge, this is the first attempt in the literature to study clustering on a stock-by-stock basis. Despite the important impact of stock clustering effect from option trading, the stock clustering effect also leads to wealth transfers among traders from both the option and stock markets. Our research will naturally raise the question on how strike price clustering could affect welfare implications for both option buyers and writers.

Overall, we show that stocking clustering effect still exists on expiration days of monthly options. This effect is much weaker on expiration days of weekly options. We also analyze the clustering effect on a stock-by-stock basis and we find that only a limited number of firms have this effect. Our results provide evidence that the introduction of weekly options does not exacerbate the stock clustering effect, but this clustering effect does not appear for all stocks with options. This is different from previous literature which studies the average sample effect. This rest of the paper is organized as follows: Section II describes the data and our results. Section III concludes the paper and discusses future research.

\section{DATA AND RESUlTS}

\section{A. Data}

We obtain the data on stocks with weekly equity options from Market Data Express. The first weekly option of a common stock was introduced by CBOE on June 25, 2010. Altogether we have 96 common stocks with weekly options traded in the period from 2010 to 2012. CBOE has also introduced weekly options for ETF products. Since ETF prices are dependent on other financial assets, we restrict our 
study to common stocks only. We obtain the expiration dates and strike prices of both the weekly options and the traditional monthly options for these 96 common stocks from the same data source. The closing stock prices are obtained from CRSP.

First we follow the same procedure of $\mathrm{Ni}$, Pearson and Poteshman (2005) to analyze the expiration dates of both monthly options and weekly options. In particular, we calculate the percentage of stock-days when the stock closes within $\$ 0.125$ of a strike price for the option expiration day, two trading days before the expiration, and two trading days after the expiration. We report all our results using $\$ 0.125$ for the cutoff point for the definition of stock clustering. That is, we define a stock is pinned to a strike price if the stock close price falls between strike price minus 0.125 and strike price plus 0.125 . Our results do not change qualitatively if we use 0.25 as the cutoff point. We only focus on the two days before and two days after because the introduction of weekly options makes nearly every Friday an option expiration day. The 96 stocks in our sample have different grid sizes of strike prices. Three, 56, 17, and 20 stocks have their option strike prices increase by $\$ 0.50, \$ 1.00, \$ 2.50$, and $\$ 5.00$, respectively. Our definition of the stock clustering is that the stock closes within $\$ 0.125$ of a strike price. Obviously, a stock with a small strike grid would have a higher probability to have the stock closing with $\$ 0.125$ of a strike price than a stock with a large strike grid. For this reason, we report the clustering percentages for different strike grids.

\section{B. Results}

Panel A of Table I shows the results for monthly options of our sample of 96 stocks during the three year period from 2010 to 2012. These results are consistent with what $\mathrm{Ni}$, Pearson and Poteshman (2005) found in their early sample period. That is, there is a higher percentage of stock clustering on the Friday when monthly options expire than the trading days before and after the option expiration day. For example, for option strike price grid of $\$ 5,11.38 \%$ of the stock-days end with the price close to one of the strike prices on monthly option expiration days, while the highest of this percentage in the four trading days surrounding the expiration day is $7.54 \%$. The difference is $3.84 \%$. We find the similar results different strike grid sizes.

Panel B of Table I presents the results for weekly options. Here the effect of stock clustering is no longer prominent. For strike grid size of $\$ 0.50$, there is no extra clustering at the weekly option expiration day at all. For strike grid size of $\$ 1$, $\$ 2.5$ and $\$ 5$, the clustering percentage is the highest on the weekly option expiration days. However, the clustering percentage on the expiration Fridays is just slightly bigger than the clustering percentage on the following Monday when there is no option expiring. For the grid size of $\$ 5$, the percentage of clustering on the weekly option expiration days is $8.25 \%$, while this percentage is $\% 7.38$ on the following Monday. Here the difference is only $0.87 \%$. Hence it appears that these weekly options do not contribute a significant clustering effect of stocks to option strikes on their expiration days.

Next we study the effect of stock clustering on a stock-by-stock basis. For each stock, we calculate the percentage of stock clustering by counting the number of days when the stock closes within $\$ 0.125$ of a strike price. We calculate this percentage for the option expiration days and for the two trading days before and two trading days after the expiration days. Then we calculate the difference between the percentage on the option expiration day and the largest of the other four percentages for the four trading days around the expiration day. If stock clustering is quite strong on option expiration day, then this difference would be consistently positive.

TABLE I: Percentage of Stocks Closing Within \$0.125 OF A StRike PRICE.

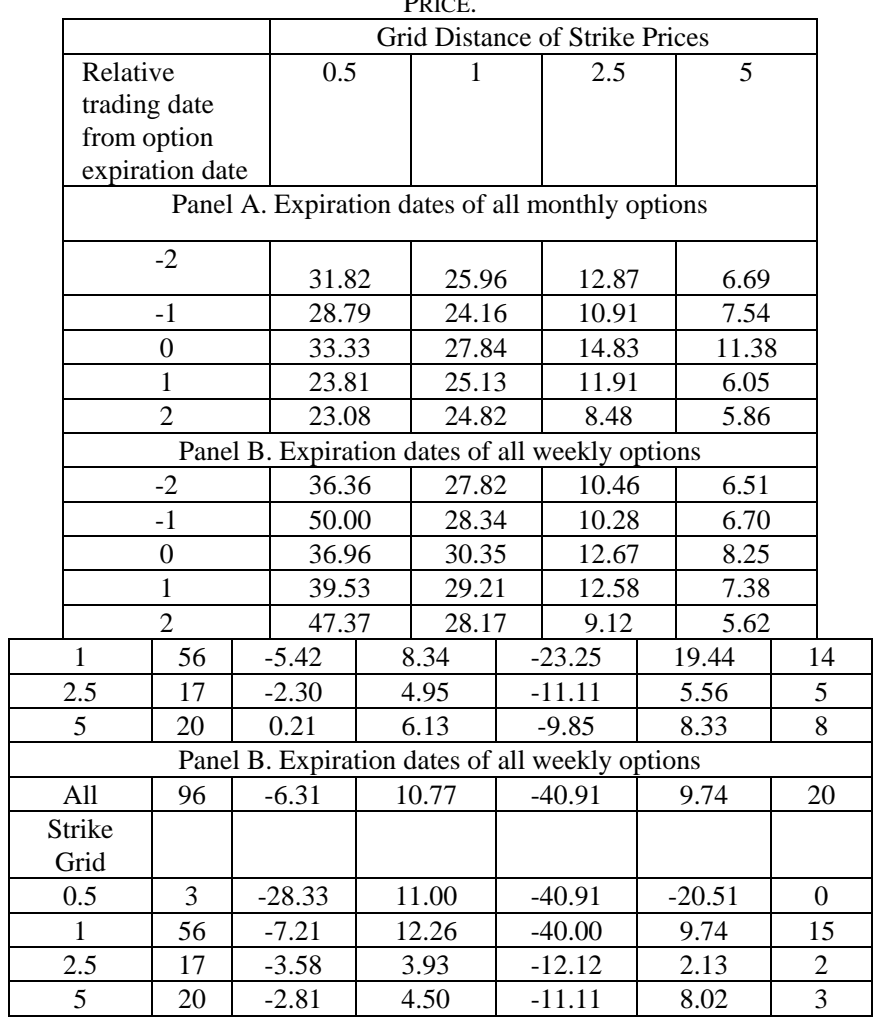

For each stock, we take the difference between the percentage of days when the stock closes within $\$ 0.125$ of a strike price on the options expiration day and the largest percentage of the two days before expiration day and the two days after expiration day. The table reports the number of stocks $(\mathrm{N})$, the mean difference (Mean), the standard deviation (Std), the minimum (Min) and the maximum (Max) of the difference, and the number of stocks with positive difference (NPos).

Table II presents the summary statistics of the difference in percentages across the 96 firms. Stock clustering on the option expiration days appears only for a limited number of firms. For monthly option expiration days, 27 out of 96 firms have higher percentage of clustering on the expiration day than the other trading days. For weekly option expiration days, this number drops to 20. Actually, out of all 96 firms, only two firms, Google (GOOG) and Western Digital Corp. (WDC), have higher percentage of clustering at both the monthly option expiration days and the weekly option expiration days. The average difference in percentages is mostly negative. On average, the clustering percentage on option expiration days is not larger than the clustering percentage on the trading days around the expiration days. 
All these results demonstrate that stock clustering on option expiration days is not uniform for all stocks. Only some firms show the impact of stocking clustering to option strike prices, and even fewer firms have this clustering effect on the weekly option expiration days.

TABLE II: STOCK CLUSTERING ANALYSIS By STOCK

\begin{tabular}{|c|c|c|c|c|c|c|}
\hline & $\mathrm{N}$ & Mean & Std & Min & Max & NPos \\
\hline \multicolumn{7}{|c|}{ Panel A. Expiration dates of all monthly options } \\
\hline All & 96 & -3.70 & 7.62 & -23.25 & 19.44 & 27 \\
\hline $\begin{array}{l}\text { Strike } \\
\text { Grid }\end{array}$ & & & & & & \\
\hline 0.5 & 3 & -5.56 & 5.56 & -11.11 & 0.00 & 0 \\
\hline
\end{tabular}

\section{CONCLUSION AND FUTURE RESEARCH}

We show that stock clustering effect still exists on expiration days of monthly listed options as observed in previous literature, but this clustering effect is not so strong and obvious on expiration days of recently listed weekly options. Besides studying this average sample effect, we find an interesting result when we take a closer look at firm-specific effect. Only a limited number of firms have this clustering effect, and close to three quarters of the firms show no clustering effect at all. This will lead to our future research in separating firm samples and further explore what characteristics will contribute to this stock clustering effect. This will help traders to identify trading schemes and help rebalancing hedging positions. This research will also contribute to the study of wealth transfer among traders in stock and option markets.

\section{REFERENCES}

[1] H. Larry, "Stock price clustering and discreteness," Review of Financial Studies, vol. 4, no. 3, pp. 389-415, 1991.

[2] H. Krishnan and I. Nelken, "The effect of stock clustering upon option prices," RISK, pp. 17-20, December 2001.

[3] N. Sophie, N. D. Pearson, and A. M. Poteshman, "Stock price clustering on option expiration dates," Journal of Financial Economics, vol. 78, no. 1, pp. 49-87, 2005.

[4] A. Gwilym, Owain, and T. Verousis, "Price clustering in individual equity options: moneyness, maturity, and price level," Journal of Futures Markets, vol. 33, no. 1, pp. 55-76, 2013.

[5] H. Chung and S. Chiang, "Price clustering in E-mini and floor-traded index futures," Journal of Futures Markets, vol. 26, no. 3, pp. 269-295, 2006.

[6] G. Benjamin and J. C. Jackwerth, "Clustering in the S\&P 500 Futures," Journal of Financial Economics, vol. 106, no. 3, pp. 566-585, 2012.

[7] A. Schwartz, B. V. Ness, and R. V. Ness, "Clustering in the futures market: Evidence from S\&P 500 futures contracts," Journal of Futures Markets, vol. 24, no. 5, pp. 413-428, 2004.

[8] W. Ohta, "An analysis of intraday patterns in price clustering on the Tokyo Stock Exchange," Journal of Banking \& Finance, vol. 30, no. 3, pp. 1023-1039, 2006.

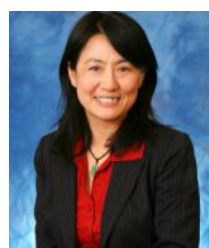

Ge Zhang was born in Shenyang, China. Zhang graduated with a $\mathrm{Ph} . \mathrm{D}$. in finance from Duke University which is in North Carolina, USA. She is currently working in William Paterson University in NJ. She has published several articles which include articles in Management Science, Journal of Risk and Insurance, Journal of Portfolio Management and etc. 